\title{
Detection of DNA Damage Response Caused by Different Forms of Titanium Dioxide Nanoparticles using Sensor Cells
}

Peng Chen ${ }^{1,2}$ and Akiyoshi Taniguchi ${ }^{1,2^{*}}$

${ }^{1}$ Cell-Materials Interaction Group, Biomaterials Unit, Nano-Bio Field, International Center for Materials Nanoarchitectonics (MANA), National Institute for Materials Science (NIMS), Japan

${ }^{2}$ Graduate School of Advanced Science and Engineering, Waseda University, Japan

\begin{abstract}
Titanium dioxide nanoparticles $\left(\mathrm{TiO}_{2} \mathrm{NPs}\right.$ ) are generally considered to be biologically inert. However, $\mathrm{TiO}_{2}$ occurs in several crystalline forms, the two most common being rutile and anatase. Although both forms are tetragonal, the different crystalline forms give rise to different physical and chemical characteristics such as hardness, refractive index and photocatalytic ability. We hypothesized that the two forms of $\mathrm{TiO}_{2} \mathrm{NPs}$ would also elicit different cellular responses. Three cell-based biosensors, using B-cell Translocation Gene 2 (BTG2), heat shock protein70B' (HSP70B') and nuclear factor kappa B (NF-kB) sensor cells, were used to determine if the different forms of $\mathrm{TiO}_{2}$ NPs cause different cellular responses. The cellular responses induced by $\mathrm{TiO}_{2} \mathrm{NPs}$ were detected using $\mathrm{HSP}^{2} \mathrm{~B}^{2}$ and NF-kB sensor cells; we found that the different forms of $\mathrm{TiO}_{2}$ NPs resulted in the same HSP70B' and NF-kB response. BTG2 expression is up-regulated by DNA damage via p53 activation. A cellular DNA damage response stimulated by different forms of $\mathrm{TiO}_{2}$ NPs was detected by our cell-based DNA damage biosensor. The results showed that an increased DNA damage response is elicited by the anatase form compared to the rutile or mixed rutile/anatase forms. Our work indicates that the crystalline form of NPs is an important point to investigate when studying the interaction between nanomaterials and cells.
\end{abstract}

Keywords: Cell-based biosensor; DNA damage response; BTG2 promoter; Titanium dioxide nanoparticles; Anatase form; Rutile form

\section{Introduction}

The increased generation, use and disposal of nanomaterialcontaining products has led to an increase in the potential exposure risk to nanomaterials for both humans and the environment [1]. For example, titanium dioxide nanoparticles $\left(\mathrm{TiO}_{2} \mathrm{NPs}\right)$ are generally considered to be biologically inert and have recently become a common commercially-used material. Increasingly, however, in vivo studies have caused researchers to be concerned that inhaled $\mathrm{TiO}_{2} \mathrm{NPs}_{\text {s could }}$ lead to inflammatory response, changes in fibroblast cell adhesion and proliferation, and even genetic damage [2-5]. Consequently, $\mathrm{TiO}_{2} \mathrm{NPs}$ have been reclassified by the IARC as a group $2 \mathrm{~B}$ carcinogen, indicating that $\mathrm{TiO}_{2}$ NPs are possibly carcinogenic to humans [6].

$\mathrm{TiO}_{2}$ occurs in nature in several crystalline forms, of which the rutile and anatase forms are the most common. The only difference between these two forms is that the anatase crystal form has a longer vertical axis. Because of its different properties, the rutile form of $\mathrm{TiO}_{2} \mathrm{NPs}$ is highly effective in the absorption of ultraviolet radiation, and thus is used in sunscreens to protect against UV-induced skin damage. In contrast, the anatase form is widely used as a photocatalyst at visible or ultraviolet wavelengths [7]. The anatase form can also oxidize oxygen or organic materials directly, with active $\mathrm{TiO}_{2} \mathrm{NP}$ photocatalysis in aqueous media generating reactive oxygen species (ROS) such as superoxide $\left(\mathrm{O}_{2}^{-}\right)$, hydroxyl radical $(\mathrm{HO} \bullet)$, hydrogen peroxide $\left(\mathrm{H}_{2} \mathrm{O}_{2}\right)$, and singlet oxygen $[8,9]$. All of these ROS can cause DNA damage [10,11]. Moreover, studies have indicated that $\mathrm{TiO}_{2}$ NPs induce photo-damage to DNA in human cells, mouse lymphoma cells, and phage [12-14].

In nature, cellular DNA damage is caused by ionizing radiation, ultraviolet light, and oxidizing agents [15]. Damage to DNA can lead to uncontrollable proliferation and cancer. In response to such damage p53, a tumor suppressor would be activated. p53 is the central sentinel transcription factor that controls the cell cycle, apoptosis, and DNA repair $[16,17]$. Recently, it was reported that p53 is one of the most important tumor suppressors in human cancers caused by zinc oxide nanoparticle-induced DNA damage [18]. B-cell translocation gene 2 (BTG2) is implicated in cell cycle regulation, DNA repair, apoptosis and senescence [19-22]. BTG2 expression is up-regulated by p53 after DNA damage induced by a genotoxic agent [23,24]. We previously demonstrated that BTG2 is a useful marker of cytotoxicity involving DNA damage, and we developed a highly sensitive DNA damage biosensor using the BTG2 promoter to detect such cytotoxicity [25].

Live cell-based biosensors have been employed to detect the cellular response stimulated by NPs. Such biosensors are highly sensitive, simple and effective compared with traditional detection methodologies [26]. We previously reported cell-based biosensors for detecting BTG2 [25], heat shock protein70B' (HSP70B') [27], and nuclear factor kappa B (NFкВ) [28]. These biosensors used promoter-reporter plasmids, which are sensitive to changes in relative promoter activation in response to toxic substances or other external stimuli. The HSP70B' biosensor is sensitive to the cellular protein denaturation response and the NF- $\mathrm{KB}$ biosensor is sensitive to the inflammatory response. We have shown that two types of sensor cells, used to detect HSP70B' and NF-кB response, could also detect the cellular response stimulated by $\mathrm{TiO}_{2} \mathrm{NPs}[28,29]$.

We here investigated whether the different $\mathrm{TiO}_{2} \mathrm{NP}$ forms cause different cellular responses by using three kinds of sensor cells. Due

*Corresponding author: Akiyoshi Taniguchi, Director of Cell-Materials Interaction Group, National Institute for Materials Science (NIMS), 1-1, Namiki, Tsukuba, Ibaraki, 305-0044, Japan, Tel: +81-29-860-4505; E-mail: taniguchi. akiyoshi@nims.go.jp

Received October 01, 2012; Accepted October 26, 2012; Published October 28 2012

Citation: Chen P, Taniguchi A (2012) Detection of DNA Damage Response Caused by Different Forms of Titanium Dioxide Nanoparticles using Sensor Cells. J Biosens Bioelectron 3:129. doi:10.4172/2155-6210.1000129

Copyright: () 2012 Chen P, et al. This is an open-access article distributed under the terms of the Creative Commons Attribution License, which permits unrestricted use, distribution, and reproduction in any medium, provided the original author and source are credited. 
to their different photocatalyst characters, the three cell types should exhibit different DNA damage responses upon exposure to different forms of $\mathrm{TiO}_{2}$ NPs. Our data show that our cell-based BTG2 biosensor using the BTG2 promoter-reporter plasmid could detect the differences in DNA damage response caused by exposure to different forms of $\mathrm{TiO}_{2}$ NPs. The results indicate the important role of crystalline form on the interaction between nanomaterials and cells. Furthermore, our cell-based biosensor could offer a means for evaluating the safety of nanomaterials for humans and the environment.

\section{Materials and Methods}

\section{Preparation of $\mathrm{TiO}_{2} \mathrm{NP}$ suspension}

The $\mathrm{TiO}_{2}$ NP preparation and characterization methods were described previously $[28,29]$. Raw titanium (IV) oxide nanoparticles with different forms (rutile, anatase, mixed rutile and anatase) were purchased from Sigma-Aldrich (St. Louis, MO, USA). For mixed samples, about $80 \%$ of the $\mathrm{TiO}_{2}$ was in the anatase form and $20 \%$ in the rutile form. $\mathrm{TiO}_{2} \mathrm{NPs}$ with different forms were dispersed in distilled water and autoclaved at $120^{\circ} \mathrm{C}$ for $20 \mathrm{~min}$. After cooling to room temperature, the $\mathrm{TiO}_{2} \mathrm{NP}$ suspensions were sonicated for $10 \mathrm{~min}$ at 200 $\mathrm{kHz}$ using a high frequency ultrasonic sonicator (MidSonic 600, Kaijo, Japan). The concentration of $\mathrm{TiO}_{2} \mathrm{NPs}$ in the samples was determined using a UV-VIS spectrophotometer (UV-1600, Shimadzu, Japan). All samples were stored at $4^{\circ} \mathrm{C}$ until use. $\mathrm{TiO}_{2} \mathrm{NPs}$ were adjusted to the desired concentration just before use by adding cell culture medium supplemented with 10\% FBS (the same medium as used for cell culture). In order to characterize $\mathrm{TiO}_{2} \mathrm{NP}$ in a cell culture condition, the $\mathrm{TiO}_{2}$ $\mathrm{NP}$ dispersed in culture medium incubated at $37^{\circ} \mathrm{C}$ in a humidified atmosphere with $5 \% \mathrm{CO}_{2}$ overnight as same as cell culture conditions. Then particle size distribution and zeta-potential of the $\mathrm{TiO}_{2} \mathrm{NP}$ solutions were measured by dynamic light scattering (Zetasizer NanoZS, Malvern Instruments, Malvern, UK). The values are shown in table 1. The sizes of these aggregated $\mathrm{TiO}_{2} \mathrm{NPs}$ are stable for several weeks, although less uniform.

\section{Cells and cell culture}

The human hepatocellular carcinoma cell line, HepG2, was cultured in Dulbecco's Modified Eagle's Medium (DMEM, Nacalai Tesque, Inc., Kyoto, Japan) supplemented with 10\% Fetal Bovine Serum (FBS, Biowest, UK), $100 \mathrm{U} / \mathrm{mL}$ penicillin, and $100 \mu \mathrm{g} / \mathrm{mL}$ streptomycin (Nacalai Tesque, Inc., Kyoto, Japan) at $37^{\circ} \mathrm{C}$ in a humidified atmosphere with $5 \% \mathrm{CO}_{2}$.

\section{Cell viability test}

Cell viability was measured using a CellTiter-Glo ${ }^{\mathrm{TM}}$ Luminescent Cell Viability Assay kit (Promega, Madison, WI, USA) according to the manufacturer's instructions. $1.0 \times 10^{4} \mathrm{HepG} 2$ cells were seeded in each well of a white opaque-walled 96-well cell culture plate (Nunclone, Roskilde, Denmark). On the second day the cells were treated with different concentrations of a suspension of $\mathrm{TiO}_{2} \mathrm{NPs}$, ranging from 1 $\mathrm{ng} / \mathrm{mL}$ to $100 \mu \mathrm{g} / \mathrm{mL}$. Cell viability was then estimated $0,3,6,12,24$,

\begin{tabular}{|l|l|l|l|}
\hline $\begin{array}{l}\text { Different forms of } \\
\mathrm{TiO}_{2} \mathrm{NP}\end{array}$ & $\begin{array}{l}\text { Raw particle size } \\
(\mathrm{nm})\end{array}$ & $\begin{array}{l}\text { Average size of NP } \\
\text { in dispersion }(\mathrm{nm})\end{array}$ & Zeta-potential $(\mathrm{mV})$ \\
\hline Anatase & $<25$ & $458.6 \pm 71.3$ & $-36.73 \pm 1.71$ \\
\hline Rutile & $<100$ & $533.5 \pm 101.0$ & $-35.35 \pm 4.65$ \\
\hline Mixed Form & $<100$ & $491.5 \pm 164.8$ & $-41.64 \pm 1.75$ \\
\hline
\end{tabular}

Data shown are the mean \pm standard deviation $(n=3)$

Table 1: Raw particle size, dispersed particle size and zeta potential of $\mathrm{TiO}_{2} \mathrm{NPs}$ with different crystalline forms.
48, 72 and $96 \mathrm{~h}$ after the addition of $\mathrm{TiO}_{2} \mathrm{NPs}$, and the cytoplasmic ATP concentration was analyzed using a Luminescent cell viability assay reader (Wako Jyunyaku, Japan).

\section{Plasmids employed}

pGL3-Control Vector (pGL3 plasmid; Promega Corp.) was employed as a blank control reporter plasmid. Three reporter plasmids were used: BTG2 promoter-reporter plasmid (BTG2 promoterreporter plasmid, the region from nt -100 to $-20 \mathrm{bp}$ of the BTG2 gene containing the p53 binding site mutation [25]), HSP70B' promoterreporter plasmid (HSP70B' promoter-reporter; the region from -287 to +112 bp of the HSP70B' promoter gene [30]) and GL4.32[luc2P/NFкB-RE/Hygro] Vector (NF-кB reporter plasmid, Promega Corp.). All the plasmids contained the SV40 promoter and enhancer sequences, resulting in strong expression of luc+ in many types of mammalian cells. The pRL-CMV vector (CMV, renilla luciferase control plasmid; Promega Corp.) contained the CMV promoter upstream of the Renilla luciferase gene and served as an internal control for variations in transfection efficiency.

\section{Construct cell-based BTG2 biosensor cells}

Reporter plasmid (blank control reporter, pGL3 plasmid or BTG2 promoter-reporter plasmid) and CMV were co-transfected into HepG2 cells to prepare a cell-based BTG2 biosensor. The transfection was performed with Lipofectamine ${ }^{\mathrm{TM}}$ LTX Reagent (Invitrogen, Carlsbad, CA, USA) according to the supplier's protocol. HepG2 cells were seeded in 48-well plates. After overnight incubation, cells were co-transfected with the plasmids using Lipofectamine ${ }^{\mathrm{TM}}$ LTX Reagent. The medium was replaced with fresh medium after $4 \sim 6$ hours transfection.

\section{Construct cell-based HSP70B' biosensor cells}

Reporter plasmid (blank control reporter, pGL3 plasmid or HSP promoter-reporter plasmid) and CMV were co-transfected into HepG2 cells to prepare a cell-based HSP70B' biosensor [29]. The transfection was performed with Lipofectamine ${ }^{\mathrm{TM}}$ LTX Reagent according to the supplier's protocol as described above.

\section{Construct cell-based NF-KB biosensor cells}

Similarly, reporter plasmid (blank control reporter, pGL3 plasmid or NF- $\mathrm{KB}$ reporter plasmid) and CMV with or without toll-like receptor 4 expression vector (TLR4, pUNO1-hTLR04a, InvivoGene, San Diego, CA, USA) were transfected into HepG2 cells to prepare a cell-based NF-кB biosensor [28]. The transfection was performed with Lipofectamine $^{\mathrm{TM}}$ LTX Reagent according to the supplier's protocol as described previously.

\section{Assessment of exposure to $\mathrm{TiO}_{2}$ nanoparticles, and luciferase activity}

One day after transfection, the culture medium was replaced with medium containing $\mathrm{TiO}_{2} \mathrm{NPs}_{\text {at }}$ the intended concentration, and then the cells were harvested and assayed for luciferase activity after the indicated exposure times. In addition, $\mathrm{TiO}_{2} \mathrm{NPs}$ were added to the culture medium immediately before the medium was added to the cells.

Luciferase activity was assessed using the Dual-Luciferase Reporter Assay System (Promega) as described previously $[28,29]$. After exposure to $\mathrm{TiO}_{2} \mathrm{NPs}$, the cells were lysed in $1 \times$ PLB buffer and luciferase, then the number of renilla light units was measured using a Lumat LB9507 (Berthold Technologies, Germany) luminometer according to the manufacturer's protocol for the Dual Luciferase assay. 
All results shown are from at least three independent tests. Results are expressed as means \pm standard deviation (SD).

\section{Results and Discussion}

HepG2 cells were exposed to NPs in order to investigate the cellular

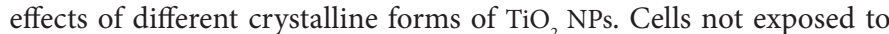
NPs acted as controls. The concentration of cytoplasmic AT signals the presence of metabolically active cells. Thus, to determine the effect on cell viability of exposure to NPs, the concentration of AT was determined after cell exposure to NPs (ranging in concentration from $1 \mathrm{ng} / \mathrm{ml}$ to $100 \mu \mathrm{g} / \mathrm{ml}$ and exposure times ranging from $3 \mathrm{~h}$ to $72 \mathrm{~h}$ ). Long exposure $(72 \mathrm{~h})$ to NPs caused a decrease in cell viability, as did increasing the NP concentration (e.g., $80 \%$ viability at $100 \mu \mathrm{g} / \mathrm{ml} \mathrm{NPs}$; Figure 1). There was no apparent effect on the viability of HepG2 if exposed for shorter times to NPs. This finding indicates that there is no significant difference in cytotoxicity caused by $\mathrm{TiO}_{2} \mathrm{NPs}$ in the anatase, rutile, or mixed form. In further assays, the concentration of NPs was standardized at $10 \mu \mathrm{g} / \mathrm{ml}$.

A cell-based biosensor for DNA damage response detection was used to investigate whether different crystalline forms of $\mathrm{TiO}_{2} \mathrm{NPs}_{\text {cause }}$ a different cellular DNA damage response. In our previous work, a BTG2 biosensor for the BTG2 promoter response detected the cytotoxicity caused by DNA strand breaks with high sensitivity [25]. It is clear from figure 2 that short exposure to NPs (from $3 \mathrm{~h}$ to $48 \mathrm{~h}$ ) results in similar BTG2 response as measured by the BTG2 promoter-luciferase reporter plasmid. However, if the NP exposure time is longer (from $72 \mathrm{~h}$ to $96 \mathrm{~h}$ ), then the different forms of $\mathrm{TiO}_{2} \mathrm{NPs}$ provide individual $\mathrm{BTG} 2$ responses: the anatase form provides the highest BTG2 response of the three samples, and the rutile form provides a lower BTG2 response than the anatase or mixed form. These distinct responses of the three samples are evident both at 72 and $96 \mathrm{~h}$. The data suggest that long exposure to $\mathrm{TiO}_{2}$ NPs could induce cellular DNA damage and possibly cancer, with the anatase form having a higher likelihood of causing DNA damage than the rutile or mixed form of $\mathrm{TiO}_{2}$ NPs. The different levels of DNA damage probably result from the photocatalytic activity of the anatase and rutile forms of $\mathrm{TiO}_{2}$. $\mathrm{TiO}_{2} \mathrm{NPs}$ in the anatase crystalline form may behave as a classical semiconductor [31]. The strong oxidative potential of the positive holes could oxidize water to create hydroxyl radicals. Thus, in comparison to the rutile form, the higher photocatalytic activity of the anatase form could generate more ROS. Although it will be difficult to obtain a microscopy image to prove that $\mathrm{TiO}_{2} \mathrm{NPs}$ are

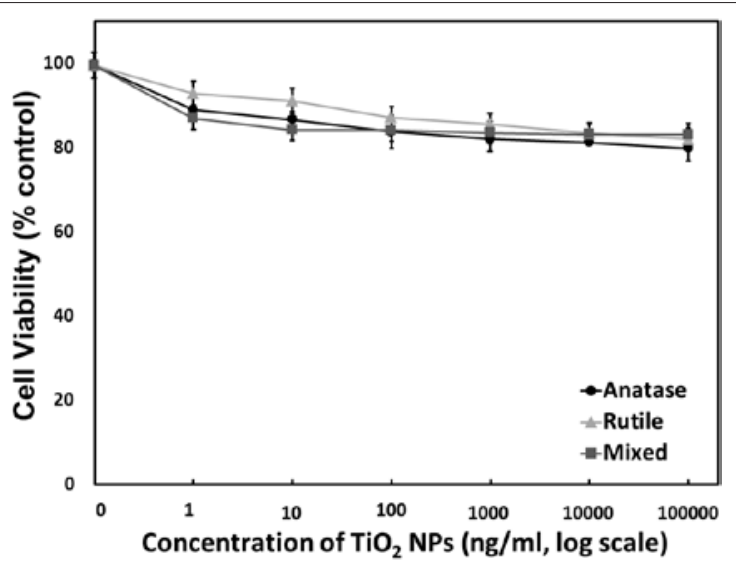

Figure 1: Cell viability determined by cytoplasmic ATP concentration. HepG2 cells were exposed to the indicated concentrations of $\mathrm{TiO}_{2} \mathrm{NPs}$ for $72 \mathrm{~h}$. The results are shown as the mean \pm s.d., $n \geq 3$ for each concentration. incorporated in the cell nucleus, $\mathrm{ROS}$ such as $\mathrm{H}_{2} \mathrm{O}_{2}$ generated by $\mathrm{TiO}_{2}$ NPs can easily diffuse into and be incorporated into the cell nucleus, leading to DNA damage [11].

We previously demonstrated that exposure to $\mathrm{TiO}_{2} \mathrm{NPs}$ causes cellular protein denaturation [29]. Therefore, a cell-based HSP70B biosensor using HSP70B' promoter-luciferase reporter plasmid was used to investigate the protein denaturation response stimulated by different forms of $\mathrm{TiO}_{2}$ NPs. The HSP70B' response in HepG2 exposed to different $\mathrm{TiO}_{2} \mathrm{NPs}$ is shown in figure 3. An over 15-fold increase in the HSP70B' response is obtained from all the samples, with no significant difference observed between the samples. This suggests that all the $\mathrm{TiO}_{2}$ NPs (anatase, rutile or mixed form) can induce a high protein denaturation response.

We previously showed that a cell-based NF-кВ biosensor comprised of NF-KB reporter and TLR4 expression vectors could detect cellular inflammatory responses. In conjunction with a cell surface receptor, TLR4, the NF-KB response induced by exposure to $\mathrm{TiO}_{2}$ NPs could be monitored [28]. In the current study, the cellular inflammatory response stimulated by different forms of $\mathrm{TiO}_{2} \mathrm{NPs}$ was also investigated. The NF-кB response was evaluated using HepG2 exposed to different $\mathrm{TiO}_{2}$ NPs (Figure 4). A similar NF-KB response, with or without TLR4 overexpression, could be elicited by all three samples, suggesting that all $\mathrm{TiO}_{2} \mathrm{NPs}$, even of different forms, can induce a similar inflammatory response.

In this work, three $\mathrm{TiO}_{2} \mathrm{NP}$ samples with different crystalline forms (anatase, rutile and mixed form) were used to test their ability to induce cellular DNA damage response. DNA damage response induced by $\mathrm{TiO}_{2} \mathrm{NPs}$ was much delayed compared to cellular protein denaturation response and inflammatory response, perhaps because it takes time for NPs to generate ROS and induce cellular DNA damage. Thus, long exposure to $\mathrm{TiO}_{2} \mathrm{NPs}$ induces a pronounced BTG2 response. The anatase form of $\mathrm{TiO}_{2}$ NPs may cause greater DNA damage due to its greater photocatalytic activity. In contrast, there was no significant difference in the degree of cellular protein denaturation and inflammatory

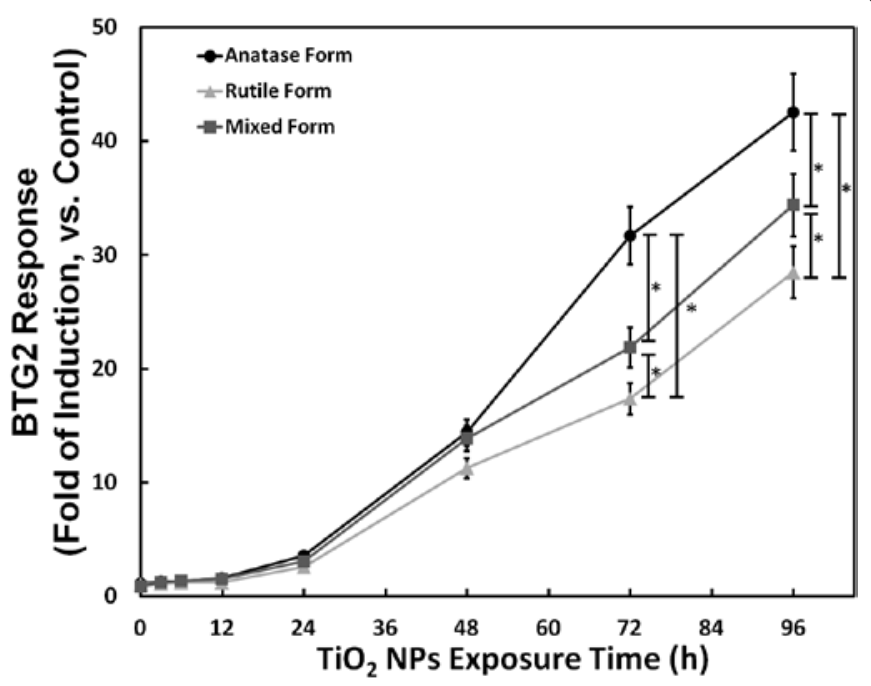

Figure 2: Time course of TiO2 NPs incubated with HepG2 cells transfected with BTG2 promoter-reporter plasmid. Scattergram of Ig-logistic growth curve plot of BTG2 response (fold induction) of HepG2 cells transfected with BTG2 promoter-luciferase reporter plasmid exposed to $10 \mu \mathrm{g} / \mathrm{mL} \mathrm{TiO}{ }_{2} \mathrm{NPs}$ for various lengths of time. Each plot was produced from at least 3 times replicated measurements. All values are presented as mean \pm s.d. $(n \geq 3)$. Data were statistically analyzed with the Student's $t$ test $\left({ }^{*} \mathrm{p}<0.05\right)$. 
Citation: Chen P, Taniguchi A (2012) Detection of DNA Damage Response Caused by Different Forms of Titanium Dioxide Nanoparticles using Sensor Cells. J Biosens Bioelectron 3:129. doi:10.4172/2155-6210.1000129

Page 4 of 5

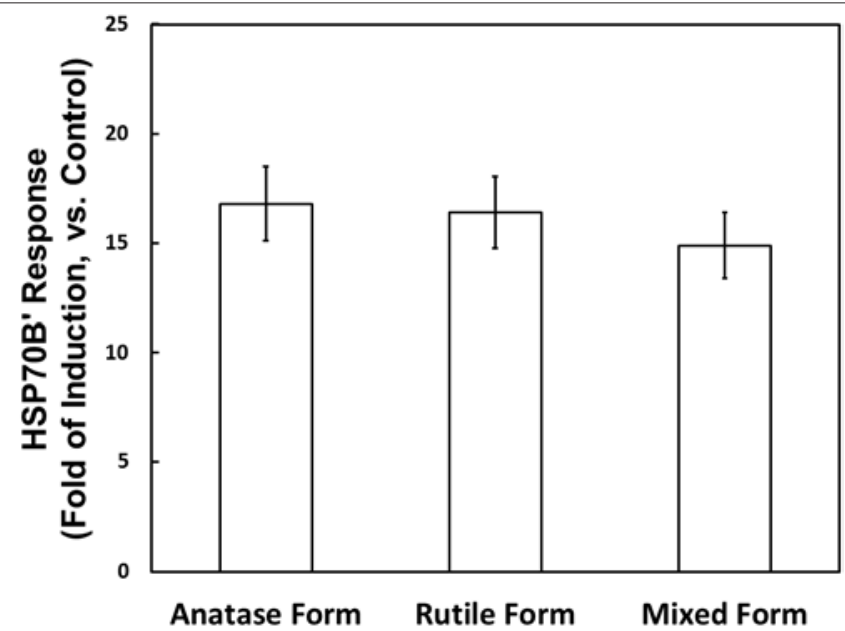

Figure 3: HSP70B' response by HepG2 cells exposed to different crystalline forms of $\mathrm{TiO}_{2}$ NPs. Histogram of HSP70B' response using HSP70B promoter-luciferase reporter plasmid (fold induction) by HepG2 exposed for 48 hours to different crystalline forms of $\mathrm{TiO} 2 \mathrm{NPs}$ (anatase form, rutile form, and mixed form, from left to right) at $10 \mu \mathrm{g} / \mathrm{mL}$. All values are presented as mean \pm s.d. $(n=3)$.

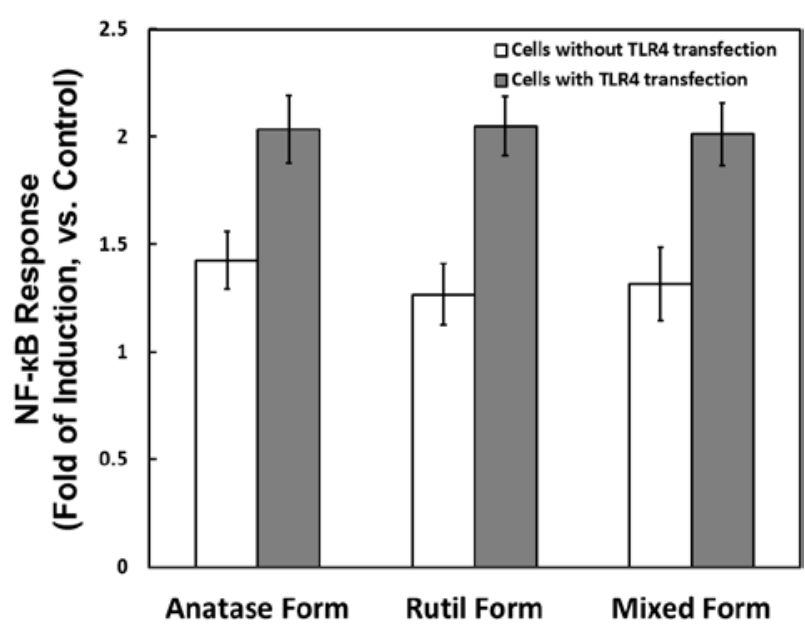

Figure 4: NF-KB response by HepG2 cells exposed to different crystalline forms of $\mathrm{TiO}_{2}$ NPs. Histogram of NF-KB response using TLR4 expression and NF-KB promoter-reporter plasmid (fold induction) by HepG2 exposed for 48 hours to different crystalline forms of $\mathrm{TiO}_{2} \mathrm{NPs}$ (anatase form, rutile form, and mixed form, from left to right) at $10 \mu \mathrm{g} / \mathrm{mL}$. White bars show the NF-kB response without the TLR4 expression vector. Black bars show the NF-kB response with the TLR4 expression vector. All values are presented as mean \pm s.d. $(n=3)$

response induced by the three $\mathrm{TiO}_{2} \mathrm{NP}$ samples. Our work shows that the crystalline form of $\mathrm{TiO}_{2} \mathrm{NPs}$ may impact the interaction between nanomaterials and cells, and that our cell-based biosensor can be used to evaluate the safety of nanomaterials.

\section{References}

1. Olson MS, Gurian PL (2012) Risk assessment strategies as nanomaterials transition into commercial applications. J Nanopart Res 14: 786-793.

2. Cui $Y$, Liu H, Zhou M, Duan $Y$, Li N, et al. (2011) Signaling pathway of inflammatory responses in the mouse liver caused by $\mathrm{TiO}_{2}$ nanoparticles. $\mathrm{J}$ Biomed Mater Res A 96: 221-229.

3. YazdiAS, Guarda G, Riteau N, Drexler SK, TardivelA, et al. (2010) Nanoparticles activate the NLR pyrin domain containing 3 (NIrp3) inflammasome and cause pulmonary inflammation through release of IL-1 $\alpha$ and IL-1 $\beta$. Proc Natl Acad Sci
U S A 107: 19449-19454.

4. Jin CY, Zhu BS, Wang XF, Lu QH (2008) Cytotoxicity of titanium dioxide nanoparticles in mouse fibroblast cells. Chem Res Toxicol 21: 1871-1877.

5. Trouiller B, Reliene R, Westbrook A, Solaimani P, Schiestl RH (2009) Titanium dioxide nanoparticles induce DNA damage and genetic instability in vivo in mice. Cancer Res 69: 8784-8789.

6. IARC Working Group on the Evaluation of Carcinogenic Risks to Humans (2010) Carbon Black, Titanium Dioxide, and Talc. IARC Monogr Eval Carcinog Risks Hum 93: 1-413.

7. Kurtoglu ME, Longenbach T, Gogotsi Y (2011). Preventing Sodium Poisoning of Photocatalytic $\mathrm{TiO}_{2}$ Films on Glass by Metal Doping. International Journal of Applied Glass Science 2: 108-116.

8. Ireland JC, Klostermann P, Rice EW, Clark RM (1993) Inactivation of Escherichia coli by titanium dioxide photocatalytic oxidation. Appl Environ Microbiol 59: 1668-1670.

9. Konaka R, Kasahara E, Dunlap WC, Yamamoto Y, Chien KC, et al. (2001) Ultraviolet irradiation of titanium dioxide in aqueous dispersion generates singlet oxygen. Redox Rep 6: 319-325.

10. Wiseman H, Halliwell B (1996) Damage to DNA by reactive oxygen and nitrogen species: role in inflammatory disease and progression to cancer Biochem J 313: 17-29.

11. Hirakawa K, Mori M, Yoshida M, Oikawa S, Kawanishi S (2004) Photoirradiated titanium dioxide catalyzes site specific DNA damage via generation of hydrogen peroxide. Free Radic Res 38: 439-447.

12. Dunford R, Salinaro A, Cai L, Serpone N, Horikoshi S, et al. (1997) Chemica oxidation and DNA damage catalysed by inorganic sunscreen ingredients. FEBS Lett 418: 87-90.

13. Nakagawa Y, Wakuri S, Sakamoto K, Tanaka N (1997) The photogenotoxicity of titanium dioxide particles. Mutat Res 394: 125-132.

14. Kashige N, Kakita Y, Nakashima Y, Miake F, Watanabe K (2001) Mechanism of the photocatalytic inactivation of Lactobacillus casei phage PL-1 by titania thin film. Curr Microbiol 42: 184-189.

15. Ciccia A, Elledge SJ (2010) The DNA damage response: making it safe to play with knives. Mol Cell 40: 179-204.

16. Hollstein M, Sidransky D, Vogelstein B, Harris CC (1991) p53 mutations in human cancers. Science 253: 49-53.

17. Lane DP (1992) Cancer. p53, guardian of the genome. Nature 358: 15-16.

18. Ng KW, Khoo SP, Heng BC, Setyawati MI, Tan EC, et al. (2011) The role of the tumor suppressor p53 pathway in the cellular DNA damage response to zinc oxide nanoparticles. Biomaterials 32: 8218-8225.

19. Duriez C, Moyret-Lalle C, Falette N, El-Ghissassi F, Puisieux A(2004) BTG2, its family and its tutor. Bull Cancer 91: E242-E53.

20. Prévôt D, Morel AP, Voeltzel T, Rostan MC, Rimokh R, et al. (2001) Relationships of the antiproliferative proteins BTG1 and BTG2 with CAF1, the human homolog of a component of the yeast CCR4 transcriptional complex: involvement in estrogen receptor alpha signaling pathway. J Biol Chem 276 : 9640-9648.

21. Tirone $F$ (2001) The gene PC3(TIS21/BTG2), prototype member of the PC3/ BTG/TOB family: regulator in control of cell growth, differentiation, and DNA repair? J Cell Physiol 187: 155-165.

22. Wheaton K, Muir J, Ma W, Benchimol S (2010) BTG2 antagonizes Pin1 in response to mitogens and telomere disruption during replicative senescence. Aging Cell 9: 747-760.

23. Rouault JP, Rimokh R, Tessa C, Paranhos G, Ffrench M, et al. (1992) BTG1, a member of a new family of antiproliferative genes. EMBO J 11: 1663-1670.

24. Rouault JP, Falette N, Guéhenneux F, Guillot C, Rimokh R, et al. (1996) Identification of BTG2, an antiproliferative p53-dependent component of the DNA damage cellular response pathway. Nat Genet 14: 482-486.

25. Wada K, Hamaguchi Y, Furukawa K, Taniguchi A (2009) DNA damage sensible engineered promoter for cellular biosensing of cytotoxicity. Biotechnol Bioeng 102: $1460-1465$

26. Taniguchi A (2010) Live cell-based sensor cells. Biomaterials 31: 5911-5915. 
Citation: Chen P, Taniguchi A (2012) Detection of DNA Damage Response Caused by Different Forms of Titanium Dioxide Nanoparticles using Sensor Cells. J Biosens Bioelectron 3:129. doi:10.4172/2155-6210.1000129

Page 5 of 5

27. Wada K, Taniguchi A, Xu L, Okano T (2005) Rapid and Highly Sensitive Detection of Cadmium Chloride Induced Cytotoxicity Using the HSP70B Promoter in Live Cells. Biotech Bioeng 92: 410-415.

28. Chen P, Migita S, Kanehira K, Sonezaki S, Taniguchi A (2011) Development of sensor cells using NF-kB pathway activation for detection of nanoparticleinduced inflammation. Sensors (Basel) 11: 7219-7230.

29. Chen P, Kanehira K, Sonezaki S, Taniguchi A (2012) Detection of cellular response to titanium dioxide nanoparticle agglomerates by sensor cells using heat shock protein promoter. Biotechnol Bioeng 109: 3112-3118.

30. Wada K, Taniguchi A, Okano T (2007) Highly sensitive detection of cytotoxicity using a modified HSP70B' promoter. Biotechnol Bioeng 97: 871-876.

31. Gogniat G, Dukan S (2007) $\mathrm{TiO}_{2}$ photocatalysis causes DNA damage via fenton reaction-generated hydroxyl radicals during the recovery period. Appl Environ Microbiol 73: 7740-7743 